Abstract THU0667 - Table 1

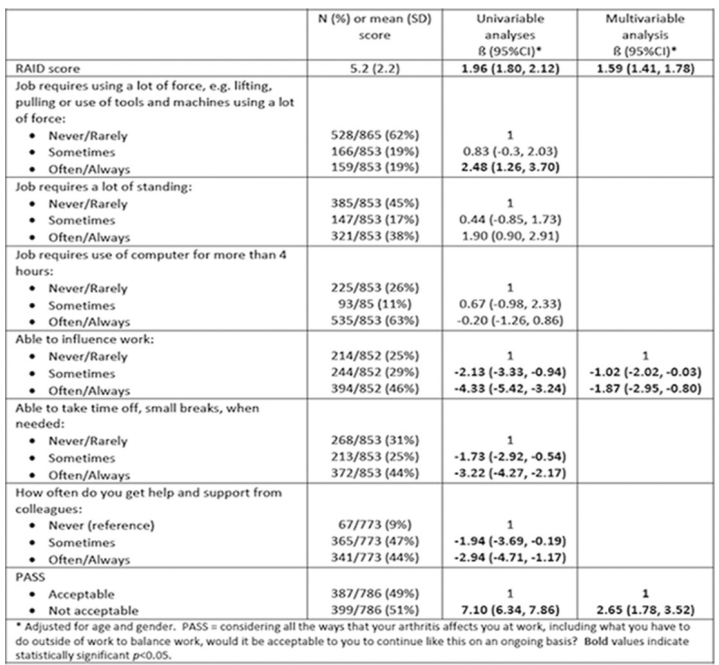

Conclusions: In this large national survey in patients with RA we found that not only disease activity, but also having control, especially the flexibility to influence work and take breaks when needed, were associated with levels of presenteeism. Preventing presenteeism should therefore be aimed at managing the disease, but also toward adapting work circumstances and finding the right balance between work requirements and personal needs.

Disclosure of Interest: None declared

DOI: 10.1136/annrheumdis-2018-eular.4121

\section{THU0668 CHOICE OF INITIAL BIOLOGIC DISEASE-MODIFYING ANTIRHEUMATIC DRUG IMPACTS HEALTHCARE RESOURCE USE AMONG PATIENTS WITH RAPIDLY PROGRESSING RHEUMATOID ARTHRITIS}

A.J. Klink ${ }^{1}$, K. Tuell ${ }^{2}$, R. Szymialis ${ }^{2}$, T. Curtice $^{2}$, K. Gupta $^{2}$, D. Nero ${ }^{1}$, B. A. Feinberg ${ }^{1} .{ }^{1}$ Cardinal Health Specialty Solutions, Dublin; ${ }^{2}$ Bristol-Myers Squibb, Princeton, USA

Background: Current management of rheumatoid arthritis (RA) in the United States is often directed by payer medical policy, typically requiring a tumour necrosis factor- $\alpha$ inhibitor (TNFi) as a first-line (1L) biologic disease-modifying antirheumatic drug (bDMARD). Recent studies ${ }^{1}$ suggest clinical subsets of patients with RA may benefit from early intervention with a non-TNFi bDMARD.

Objectives: To characterise 6 month healthcare resource utilisation (HRU) for patients with RA in the United States when treated with different $1 \mathrm{~L}$ bDMARDs (1L TNFi or $1 \mathrm{~L}$ abatacept) and assess the impact of initial bDMARD selection on 6 month HRU.

Methods: Early, rapidly progressive RA (eRPRA) is a recognised clinical entity comprising a constellation of clinical and biomarker features: anti-cyclic citrullinated peptide-2 positivity (ACCP+), DAS28 (CRP) $\geq 3.2$, symptomatic synovitis in $>2$ joints for $>8$ weeks and onset of symptoms $\leq 2$ years. Physicians with adult RA patients meeting these criteria for eRPRA used patient medical records to provide patient data via an electronic case report form. Patients received either abatacept or TNFi in 1L. Patient characteristics and HRU in the first 6 months of bDMARD treatment were summarised and compared across treatment groups. Odds ratios (OR) of $\mathrm{HRU}$ were estimated using multivariable logistic regression to adjust for baseline indicators of disease severity and patient mix (age, sex, race, ethnicity, region, payer type, time from RA diagnosis to bDMARD start, baseline concomitant medication use, baseline swollen joint count [SJC], tender joint count [TJC], Clinical Disease Activity Index [CDAI], extra-articular manifestations).

Results: There were 60 abatacept and 192 TNFi patients in $1 \mathrm{~L}$. Mean ages at bDMARD start were 49.1 and 49.9 years, and mean times from RA diagnosis to bDMARD initiation were 1.5 and 6.4 months for abatacept and TNFi users, respectively (all $p>0.05$ ). At bDMARD start, patients with eRPRA treated with abatacept or TNFi, respectively, had mean SJC of 6.8 and 7.3, TJC of 10.4 and 10.2, ESR of 39.8 and $44.0 \mathrm{~mm} / \mathrm{h}, \mathrm{CRP}$ of 8.1 and $8.2 \mathrm{mg} / \mathrm{L}$ and numbers of bony erosions of 1.2 and 1.7 (all $p>0.05$ ). $45 \%$ and $47 \%$ ( $p>0.05)$ of abatacept and TNFi users, respectively, had concomitant oral corticosteroids at bDMARD start. A lower proportion of patients treated with abatacept had hospitalizations (72 vs $88 \%$ ), emergency department (ED) visits (75 vs $90 \%$ ) and MRI (65 vs $82 \%$ ) (all $\mathrm{p}<0.05$ ), while use of ultrasound ( 82 vs $88 \%$ ) and radiography ( 88 vs $93 \%$ ) during the first 6 months of bDMARD treatment was similar. After adjusting for patient characteristics, those treated with $1 \mathrm{~L}$ abatacept had significantly lower odds of hospitalisation (OR $0.42 ; 95 \% \mathrm{Cl} 0.18,0.95$ ), ED visits (OR $0.39 ; 95 \% \mathrm{Cl} 0.16$ 0.93 ) and $\mathrm{MRI}(\mathrm{OR} 0.45 ; 95 \% \mathrm{Cl} 0.21,0.97)$ compared with $1 \mathrm{~L}$ TNFi (all $p<0.05$ ). Adjusted odds of achieving CDAI low disease activity within 100 days of bDMARD favoured $1 \mathrm{~L}$ abatacept vs $1 \mathrm{~L}$ TNFi (OR 3.26; 95\% Cl 1.32, 8.07; $\mathrm{p}<0.05$ ).

Conclusions: After adjusting for baseline disease severity, patients treated with $1 \mathrm{~L}$ abatacept were less likely to have hospitalizations, ED visits and MRIs during the first 6 months of bDMARD treatment compared with those who received a $1 \mathrm{~L}$ TNFi.

\section{REFERENCE:}

[1] Turesson C, et al. Arthritis Rheum 2014;66(S10);S217 abstract 501.

Disclosure of Interest: A. Klink Consultant for: Bristol-Myers Squibb, Janssen, Celgene, EMD Serono, Ipsen, Kite, Merck, Novartis, Vertex, Amgen, Astellas, Heron, AbbVie, Array, Seattle Genetics, Employee of: Cardinal Health, K. Tuell Employee of: Bristol-Myers Squibb, R. Szymialis Shareholder of: Bristol-Myers Squibb, Employee of: Bristol-Myers Squibb, T. Curtice Employee of: Bristol-Myers Squibb, K. Gupta: None declared, D. Nero Consultant for: Bristol-Myers Squibb, Employee of: Cardinal Health, B. Feinberg: None declared DOI: 10.1136/annrheumdis-2018-eular.2114

\section{THU0669 A SELF-REPORT SYMPTOM CHECKLIST ON A MULTIDIMENSIONAL HEALTH ASSESSMENT QUESTIONNAIRE (MDHAQ) TO CAPTURE A "POSITIVE REVIEW OF SYSTEMS" AS A STANDARD QUANTITATIVE, AND INFORMATIVE "SCIENTIFIC" CLUE TO FIBROMYALGIA SIMILAR TO MODIFIED CRITERIA FOR FIBROMYALGIA}

T. Pincus, S. Jamal, I. Castrejon. Rheumatology, Rush University Medical Center, Chicago, USA

Background: The scientific method is based on recording information as quantitative standard data rather than as narrative descriptions, to test possible value in diagnosis, management, and outcomes. This approach generally is applied to laboratory tests and other data from high technology sources. However, information from a patient history and physical examination can be analysed for scientific validity if collected in as standard, quantitative and reproducible data. A symptom checklist of 60 items was initially designed as a review of systems to screen for symptoms and possible adverse events of medications, for which it has been helpful. It has also been observed that patients who report a large number of symptoms may provide a clue to the presence of fibromyalgia (FM);Clin Exp Rheumatol. 2004. 22:453-61).

Objectives: To compare results of a 60 -item symptom checklist on a multidimensional health assessment questionnaire (MDHAQ) vs the modified 2016 revised preliminary diagnostic criteria for fibromyalgia (Sem Arth Rheum 46:319-329, 2016).

Methods: All patients seen at an academic rheumatology clinic complete an MDHAQ;J Rheumatol 2005 32:1432-9) at each visit, which includes a 60-item symptom checklist. In April-July 2017, patients also completed a questionnaire to identify the 2016 revised preliminary diagnostic criteria for FM. The likelihood of reporting each symptom by a patient with RA who did not have FM was compared to patients who met 2016 criteria for FM using a chi-square test. Receiver operator characteristic (ROC) curves were performed of the 60 symptom checklist as well as the 10 most discriminatory symptoms vs the FM criteria.

Abstract THU0669 - Table 1. Proportion of patients with rheumatoid arthritis (RA) who did not meet fibromyalgia criteria versus patients with primary or secondary fibromyalgia to meet fibromyalgia criteria who responded positively regarding the 10 most discriminatory symptoms on a symptom checklist

\begin{tabular}{lccc}
\hline Symptom & $\begin{array}{c}\text { RA } \\
(84)\end{array}$ & $\begin{array}{c}\text { FM } \\
(110)\end{array}$ & Chi2* $^{*}$ \\
\hline Muscle pain, aches, or cramps & $30(35)$ & $100(31)$ & 65.6367 \\
Muscle weakness & $16(19)$ & $82(75)$ & 58.6852 \\
Dizziness & $11(13)$ & $65(59)$ & 42.2875 \\
Headaches & $25(30)$ & $84(76)$ & 42.0177 \\
Problems with thinking & $7(8)$ & $57(52)$ & 40.7405 \\
Problems with memory & $12(14)$ & $65(59)$ & 39.9442 \\
Neck pain & $29(35)$ & $87(79)$ & 39.3505 \\
Problems with sleeping & $30(36)$ & $88(80)$ & 39.2017 \\
Numbness or tingling of arms or & $16(19)$ & $70(64)$ & 38.3709 \\
legs & & & \\
Unusual fatigue & $23(27)$ & $79(72)$ & 37.7207 \\
\hline
\end{tabular}

*all $p<0.001$ 
Results: We studied 84 patients with RA who did not meet FM criteria vs 110 patients who met FM criteria - no differences were seen between patients with primary or secondary FM who met criteria. Patients who met FM criteria were more likely to report each of the 60 symptoms. The 10 symptoms that were most discriminatory of RA vs FM are illustrated in the table 1. A ROC curve for the 60 symptoms vs the FM Criteria had an area of 0.896 (Confidence interval 0.8720.925 ), and for the 10 most discriminatory symptoms of 0.8975 (Confidence interval 0.8667-0.928)

Conclusions: A simple MDHAQ symptom checklist may be informative in routine rheumatology care to identify possible primary and secondary FM in agreement with FM criteria. The MDHAQ may provide a useful and feasible alternative to FM Criteria for busy clinical settings.

Disclosure of Interest: T. Pincus Shareholder of: Dr. Pincus holds a copyright and trademark on MDHAQ and RAPID3 for which he receives royalties and license fees. All revenue is used to support further development of quantitative questionnaire measures for patients and doctors in clinical rheumatology care., S. Jamal: None declared, I. Castrejon: None declared

DOI: 10.1136/annrheumdis-2018-eular.7524

\section{THU0670 A REUMATOLOGIST'S EVALUATION OF HOW EFFICIENCIES IN THE MANAGEMENT OF PAINFUL LUMBAR SYNDROME IN WORK DISABILITY CREATES BENEFITS \& SAVINGS}

V.M. Flores Rodríguez ${ }^{1}$, F. Díaz Gonzalez ${ }^{1}$, S. Bustabad Reyes ${ }^{2}$, M. Carballo Correa ${ }^{3} .{ }^{1}$ Departament of Rheumatology, ${ }^{2}$ Departamento of Rheumatology, University Hospital of the Canary Islands; ${ }^{3} \mathrm{PhD}$ student of the Pharmacy Faculty, University of La Laguna, San Cristóbal de La Laguna, Spain

Background: Musculoskeletal disorders are the most important cause of sick leave in the world. ${ }^{1}$ Lumbar pain is the main cause of temporary incapacity whith significant socio-economic impact.

Objectives: Test efficiency of Healthcare approach by rheumatologist as savings in indirect costs e.g days off work and in direct costs derived from medical assistance in controlled patient group on sick leave diagnosed with lumbar pain.

Methods: 2 year quasi-experimental bi-directional analytical design trial. Retrospective cohort in Control Group- CG and prospective cohort for intervention group -IG. Two groups, IG and CG respectively contain 150 (56\% women aged 47.5 years \pm 10$)$ and $172(48.8 \%$ women aged 44.2 years \pm 10$)$ working age patients with lumbar pain. Study made by Program for the Management of Temporary Disability implemented by Rheumatology Service of University Hospital of the Canary Islands. Study included early intervention, protocol in diagnostic tests and treatment. This study was evaluated by the Ethics Committee of the research of the University Hospital of Canary Islands fulfilling the requirements of suitability. Results: $24 \%$ of patients of IG fit to return to work after first appointment. Maximum efficiency of study between 30 thand 45 th day of sick leave. At 45 days $8 \%$ IG and 18,6\% CG remained on sick leave. Average reduction 26 days of sick leave respect to $C G$, a total saving of 6.182 days of sick leave over 1 year, with efficiency of $62,2 \%$. Saving in direct costs in IG over CG: medicaments, complementary tests, inter-consultations, follow up $48 \%$. Absolute saving of $38.891 €$, or equivalent $256.680 €$ for 1.000 patients. National Institute of Social Security Indirect sick leave costs $67,1 \%$. Absolute saving of $129.883 €$, or equivalent of $857.227 €$ for 1.000 patients. Indirect costs savings for Employers for intervention $50 \%$. Absolute saving $108.649 €$, or equivalent to $717.083 €$ for 1.000 patients. Workers in program saved $50 \%$ in salary loss. Average saving $605 € /$ worker. Total saved by implementation of program to State, to worker, to Employer$360.142 €$. Program Cost effective, producing average annual saving per patient of $259 €$ and average reduction of sick leave days of 41,2 . Program cost efficiencies produced. Every day of disability saved equivalent to implementation cost of $5,06 €$. Cost-benefit program produced for State saving of $6,44 €$ for every $€$ invested in implementation $137.248 €$. Program had $93,8 \%$ patient acceptance expressing maximum satisfaction.

Conclusions: Management of disability by rheumatologist highly profitable given low program implementation cost compared to savings generated for State and Employer.

\section{REFERENCE:}

[1] WHO.The burden of musculoskeletal conditions at the star of the millenium. En: WHO Technical Report Series: 919.Geneva 2003.

Disclosure of Interest: None declared

DOI: 10.1136/annrheumdis-2018-eular.3573
THURSDAY, 14 JUNE 2018

\section{Epidemiology, risk factors for disease or disease progression}

THU0671

STANDARDISED MORTALITY RATES FOR SYSTEMIC LUPUS ERYTHEMATOSUS IN WESTERN AUSTRALIA FROM 1980 TO 2015

W.D. Raymond ${ }^{1}$, D. Preen ${ }^{2}$, H. Keen ${ }^{1}$, C. Inderjeeth ${ }^{1}$, J. Nossent ${ }^{1} .{ }^{1}$ School of Medicine and Pharmacology, ${ }^{2}$ School of Population and Global Health, The University of Western Australia, Perth, Australia

Background: Patients with Systemic Lupus Erythematosus (SLE) are at increased risk of premature mortality. However, population-level mortality rates for SLE have not yet been reported in Australia.

Objectives: Calculate the standardised mortality rates (SMR) for SLE patients in Western Australia (WA) from 1980 to 2015, overall and by age and gender.

Methods: Utilising whole-population linked hospital admission, cancer registration and death data for WA from 1980 to 2015, we compared characteristics and calculated SMRs $(95 \%$ CI) for patients with SLE (ICD-9-CM 695.4 710.0, ICD-10 AM L93.0, M32.0) against controls (5:1) free of rheumatic disease after matching for age, gender, Aboriginality and year of first SLE event.

Results: SLE patients $(n=2,868)$ and controls $(n=12,785)$ recorded 1335 and 4400 deaths with crude mortality rates of $56.3 / 1,000$ vs $37.1 / 1,000$ person-years respectively. SLE patients were approximately 10 years younger (71 vs 81 years) and 2.2-times more likely hospitalised at death $(\mathrm{p}<0.001)$. The age-adjusted SMR (per 1,000) for SLE patients was $4.4(95 \% \mathrm{Cl} 3.0,5.8)$, and higher in females 5.4 $(95 \% \mathrm{Cl} 3.5,7.4)$ than in males $3.4(95 \% \mathrm{Cl} 1.5,5.4)$. Five-year period SMRs were $8.6(95 \% \mathrm{Cl} 5.0,12.2)$ between $1990-1994,9.3(95 \% \mathrm{Cl} 4.4,14.2)$ between 1995 $1999,7.6(95 \% \mathrm{Cl} 3.1,12.1)$ between $2000-2004,4.5(95 \% \mathrm{Cl} 0.2,8.7)$ between 2005-2009, and 4.9 (95\%Cl 1.32, 8.5) between 2010-2015.

Conclusions: SLE patients in WA experienced a decline in SMRs over time, but remain at increased risk of premature mortality. Within the limitations of administrative linked data, SLE in WA associates with an average reduction in life span of 10 years.

Acknowledgements: The authors wish to thank the staff at the Western Australian Data Linkage Branch and Emergency Department Data Collection, Hospital Morbidity Data Collection, WA Cancer Registry and Death Registrations.

The Rheumatology Group of UWA (JN) was supported by an unrestricted grant from the Arthritis and Osteoporosis Foundation of Western Australia (AOWA). The AOWA provided WR with a PhD Scholarship in Memory of Johan Donald Stewart. This research was also supported by an unrestricted Australian Project Grant from Arthritis Australia.

Disclosure of Interest: None declared

DOI: 10.1136/annrheumdis-2018-eular.6142

\section{THU0672 IMPACT OF PREGNANCY ON PHYSICAL FUNCTION AND HEALTH-RELATED QUALITY OF LIFE IN WOMEN WITH AXIAL SPONDYLOARTHRITIS}

K. Ursin ${ }^{1}$, S. Lydersen ${ }^{2}$, J. Skomsvoll ${ }^{1}$, M. Wallenius ${ }^{1} .{ }^{1}$ National advisory unit on pregnancy and rheumatic diseases, Department of rheumatology, St. Olavs hospital; ${ }^{2}$ Regional center for child and youth mental health and child welfare, Faculty of Medicine and health sciences, Norwegian University of science and technology, Trondheim, Norway

Background: The only previous study exploring the impact of pregnancy on health-related quality of life in women with axial spondyloarthritis (axSpA), included only ten women. ${ }^{1}$

Objectives: To prospectively study physical function and health-related quality of life in a large cohort of women with axSpA during and after pregnancy, using Bath Ankylosing Spondylitis Functional Index (BASFI) and three of the dimensions of RAND 36-Item Health Survey (RAND-36): Physical functioning, bodily pain and mental health.

Methods: RevNatus is a Norwegian nationwide register designed for the followup of pregnant women with rheumatic diseases. Our study comprised 179 pregnancies in 166 women with axSpA included in RevNatus between 2006 - 2016 The women had seven visits at a rheumatology unit; before pregnancy, in each trimester, and six weeks, six months and twelve months postpartum. BASFI-scores and scores of RAND-36 physical functioning, bodily pain and mental health from each visit were analysed in a linear mixed model. BASFI has an overall index score between 0 ("no functional impairment") and 10 ("maximal functional 